\title{
22. MAGNETIZATION OF SEAMOUNT-DERIVED SEDIMENTS FROM SITE 869 INFERRED FROM DOWNHOLE MAGNETOMETER LOGS ${ }^{1}$
}

\author{
Yoshifumi Nogi, ${ }^{2}$ John A. Tarduno, ${ }^{3}$ and William W. Sager ${ }^{4}$
}

\begin{abstract}
Magnetic field variations from downhole magnetometer logs were measured at Site 869. Magnetic field component readings were made with both the Japanese downhole three-component magnetometer (JDTCM) and the general purpose inclinometer tool (GPIT) log. The latter only provided two horizontal components. Some discrepancies between magnetic field variations by the JDTCM and by the GPIT were noted. The origins of these discrepancies have not been identified, but some of the discrepancies are likely related to resolution differences between the JDTCM and GPIT. Magnetic field variation data from the GPIT were used after accounting for these discrepancies.

Downhole magnetometer logs suggest that almost all the magnetization is remanent and acquired in the Southern Hemisphere, but that in some parts there is an induced or viscous magnetization. Normal polarity magnetization was observed below 380 mbsf. A zone of reversed polarity magnetization is suggested between 319 and $378 \mathrm{mbsf}$ and is interpreted as recording reversed-polarity Chron 33R. Magnetic field variations between 334 and $338 \mathrm{mbsf}$ within the reversed magnetization zone imply a possible short normal polarity interval, although this zone is complex and may record various overprint components.

Magnetic units and subunits are determined using magnetic boundaries from downhole magnetometer logs as well as magnetostratigraphy by paleomagnetic study, and lithologic and logging units identified by shipboard study. Apparent inclinations in each magnetic unit indicate two inclination groups $\left(6.9^{\circ}-13.6^{\circ}\right.$ and about $\left.22^{\circ}\right)$. The apparent inclination is shallower than that obtained from paleomagnetic study. The difference is probably caused by induced magnetization.
\end{abstract}

\section{INTRODUCTION}

Downhole measurements are useful complements for coring studies because they provide nearly continuous readings of geological and physical properties of the borehole wall. One parameter that can be readily measured is the geomagnetic field, which contains information about magnetization of the surrounding materials in the borehole. The magnetization reflects not only the content of magnetic minerals, but also the record of geomagnetic field history (e.g., reversals and paleolatitude).

A fluxgate-type Japanese downhole three-component magnetometer (JDTCM) has been used to measure the magnetic field in oceanic crust and seamounts that have strong magnetizations $(>1 \mathrm{~A} / \mathrm{m})$. This type of magnetometer is convenient for measuring strong magnetizations and for obtaining vector magnetic data. Several downhole three-component magnetometer logs have been recorded in the oceanic crust to reveal the magnetic structure of the oceanic crust and the origin of magnetic anomaly lineations (Kinoshita et al., 1989; Hamano and Kinoshita, 1990). Downhole magnetometer logs run in seamounts revealed their magnetic structure during Leg 143 (Nogi et al., this volume).

Volcaniclastic turbidites have an intensity between that of basalt $(>1 \mathrm{~A} / \mathrm{m})$ and sedimentary rocks $(\sim 0.001 \mathrm{~A} / \mathrm{m})$. Therefore, magnetic variations caused by volcaniclastic sediments are detectable by fluxgate-type sensors. We had an opportunity to measure volcaniclastic turbidites at Site 869 using the JDTCM. Magnetic field data were also available from the general purpose inclinometer tool (GPIT), used as an orientation tool for the formation microscanner log, and were used to obtain more information about magnetization in the

\footnotetext{
${ }^{1}$ Winterer, E.L., Sager, W.W., Firth, J.V., and Sinton, J.M. (Eds.), 1995. Proc. ODP, Sci. Results, 143: College Station TX (Ocean Drilling Program).

${ }^{2}$ Geochemical Research Department, Meteorological Research Institute, Tsukuba, Ibaraki 305, Japan.

${ }^{3}$ Department of Earth and Environmental Sciences, University of Rochester, Rochester, NY 14627, U.S.A

${ }^{4}$ Department of Oceanography, Texas A\&M University, College Station, TX 77843 , U.S.A.
}

borehole. We present a comparison between magnetic field data by JDTCM and GPIT and the magnetization of volcaniclastic sediments in the borehole from downhole magnetometer logs.

\section{JAPANESE DOWNHOLE THREE-COMPONENT MAGNETOMETER}

Downhole magnetometer log measurements were made between 239 and 725 mbsf at Site 869 with the JDTCM. The JDTCM has a sensitivity of about $2 \mathrm{nT}$. Unfortunately, the horizontal component of the magnetic field variations was not recoverable as a result of rapid tool rotations in the hole. High-amplitude $(\sim 30,000 \mathrm{nT})$, sharp decreases in the horizontal magnetic field were in the record. Similar sharp decreases in the horizontal magnetic field were also recorded within weakly magnetized limestone sections at Sites 865 and 866, where the logging cable speed was faster than $2000 \mathrm{~m} / \mathrm{hr}$ (Nogi et al., this volume). An abrupt change of the tool orientation, owing to the fast logging cable speed and the unstable hole conditions, are suggested as the cause of these variations; however, the origin of only sharp decreases have not been identified at the moment (Nogi et al., this volume). Although logging speed is slow $(<1000 \mathrm{~m} / \mathrm{hr})$ at Site 869 , the unstable hole condition probably cause the abrupt change of tool orientation. The vertical component of the magnetic field variations was also contaminated by the rapid tool rotation, but it was possible to remove this effect by filtering. Magnetic variations in the vertical component having a wavelength shorter than $4 \mathrm{~m}$ were filtered out by a window-type filter to remove the tool-rotation effect.

Magnetic boundaries were determined using only the vertical component, applying the method of Nogi et al. (this volume). The spatial differential of the vertical field component was calculated. The absolute value of these was used for determining magnetic boundary, rather than the intensity of the spatial differential of the downhole magnetic field (ISDDM) (see Nogi et al., this volume). Magnetic variations of the horizontal and vertical components at the magnetic boundaries exhibit similar behavior regardless of sign, assuming that the hole has a circular cross section with azimuthal homogeneity (e.g., Hamano and Kinoshita, 1990; Nogi et al., this volume). Therefore, magnetic boundaries can be determined from significant peaks of 
variations in the absolute value of the vertical component spatial differential in the borehole.

\section{GENERAL PURPOSE INCLINOMETER TOOL}

Magnetic field data from the GPIT were used to yield more information about the magnetization at Site 869. The GPIT contains a three-component fluxgate magnetometer for providing tool orientation with respect to the Earth's magnetic field. Its sensitivity is about $50 \mathrm{nT}$ (A. Dumont, Schlumberger Co. Ltd., pers. comm., 1993). Magnetic field variations of the vertical and horizontal components obtained by the GPIT at Site 869 and those of the vertical component by the JDTCM are shown in Figure 1.

Although the curves are similar, some discrepancies between the vertical components recorded by the GPIT and JDTCM were observed. The overall agreement of these two curves implies that the readings are valid and reflect geology. Some short-wavelength (about $5 \mathrm{~m}$ ) magnetic variations of the vertical component observed by the JDTCM were not seen in the GPIT curve (Fig. 1). Likewise, shortwavelength (about $5 \mathrm{~m}$ ) magnetic variations were noted in the GPIT horizontal component, but are not reflected in the GPIT vertical component. However, these variations are in good agreement with the JDTCM vertical component variations. Power spectrum pattern of the GPIT horizontal component is similar to that of the JDTCM vertical component between the wavelength of 4 and $50 \mathrm{~m}$ (Fig. 2). In contrast, the power spectrum pattern of the GPIT vertical component is different from that of the GPIT horizontal component (i.e., wavelengths shorter than $10 \mathrm{~m}$ ) (Fig. 2). This is supporting evidence that the JDTCM short-wavelength vertical component magnetic variations are caused by the surrounding rock, not by tool rotation or artificial effects, and that the vertical component of the GPIT magnetic field is less sensitive for variations whose wavelength is shorter than $10 \mathrm{~m}$. However, magnetic field variations in the GPIT horizontal component seem smoother than those of the JDTCM vertical component. The short wavelength $(<10 \mathrm{~m})$ power spectrum of the GPIT horizontal component also decreases to a low level. This suggests that the GPIT magnetic readings are less sensitive to short-wavelength variations than measurements by the JDTCM, an effect caused mostly by the low resolution of the GPIT's magnetic sensor. These observations suggest that magnetic field variations of the vertical and horizontal components recorded by the GPIT, with wavelengths longer than $10 \mathrm{~m}$, are reliable for estimating gross features of magnetization in the borehole.

The absolute value of the GPIT vertical component magnetic field is different from that of the JDTCM, with this difference being almost $1000 \mathrm{nT}$ (Fig. 1 and Table 1). Therefore, relative changes of the GPIT magnetic field data with wavelength longer than $10 \mathrm{~m}$ were used for the analysis.

\section{DATA PROCESSING}

Magnetic boundaries are defined from the GPIT ISDDM as well as the absolute value of the spatial differential of the vertical component of the JDTCM magnetic field. Only peaks that exceed threshold levels of $100 \mathrm{nT} / \mathrm{m}$ for the GPIT ISDDM and were $80 \mathrm{nT} / \mathrm{m}$ in the absolute value of the JDTCM spatial differential were regarded as magnetic boundaries. The magnetic units and subunits are determined using magnetic boundaries as well as magnetostratigraphy by paleomagnetic study (Sager et al., this volume), and lithologic and logging units identified by shipboard study (Sager, Winterer, Firth, et al., 1993).

The inclination resulting from a single, homogeneous, cylindrical magnetized body, called the apparent inclination, is obtained from the ratio between the spatial differential of the vertical to the horizontal component of the magnetic field (Nogi et al., this volume). The ratio between the spatial differential values of the vertical to horizontal components of the magnetic field recorded by the GPIT in each magnetic unit were obtained from linear regression (Fig. 3). The apparent
Site 869

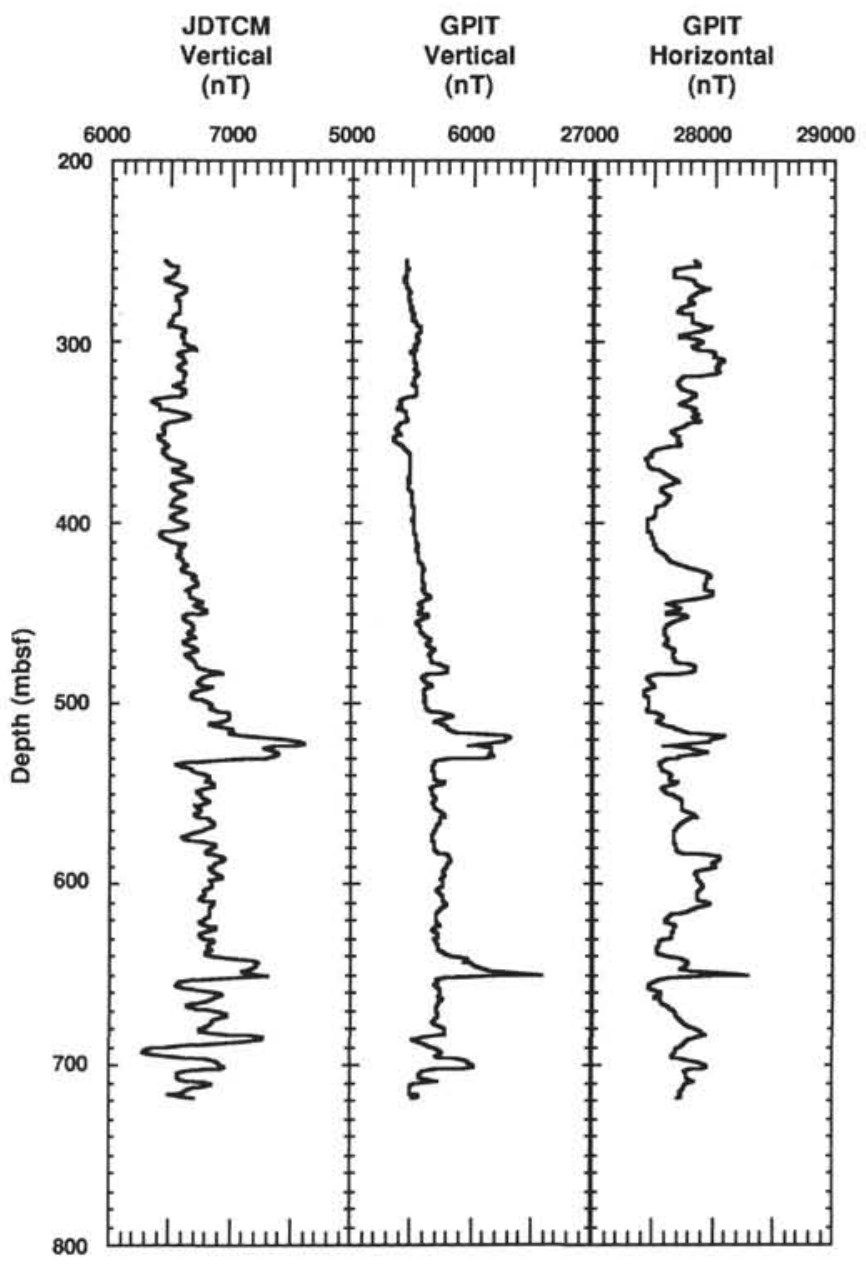

Figure 1. Horizontal and vertical magnetic field variations by the Japanese downhole three-component magnetometer (JDTCM) and the general purpose inclinometer tool (GPIT) at Site 869.

Table 1. Vertical and horizontal magnetic field calculated from IGRF 1990 (IAGA Division V Working Group 8, 1991) and mean value of components from JDTCM and GPIT at Site 869.

\begin{tabular}{|c|c|c|c|c|c|}
\hline & IGRF90 & JDTCM & $\begin{array}{c}\text { Difference } \\
\text { (JDTCM-IGRF90) }\end{array}$ & GPIT & $\begin{array}{c}\text { Difference } \\
\text { (GPIT - IGRF90) }\end{array}$ \\
\hline Horizontal (nT): & 33729 & - & $\overline{1}$ & 27718 & -6011 \\
\hline Vertical (nT): & 6246 & 6709 & 463 & 5623 & -623 \\
\hline
\end{tabular}

inclination of each unit was calculated (Table 2) using the ratio between spatial differential values.

The magnetization acquired in the Northern or the Southern Hemisphere was determined from the magnetic variations in each magnetic subunit. Vertical and horizontal magnetic field vary in the opposite sense, if the magnetization of surrounding materials are acquired in the Northern Hemisphere. In the case of magnetization originating in the Southern Hemisphere, these vary in the same sense. Therefore, variations in the same sense in the JDTCM vertical and the GPIT horizontal components in a given unit were regarded as representing a magnetization that originated in the Southern Hemisphere; others are regarded as having been acquired in the Northern Hemisphere. 
A

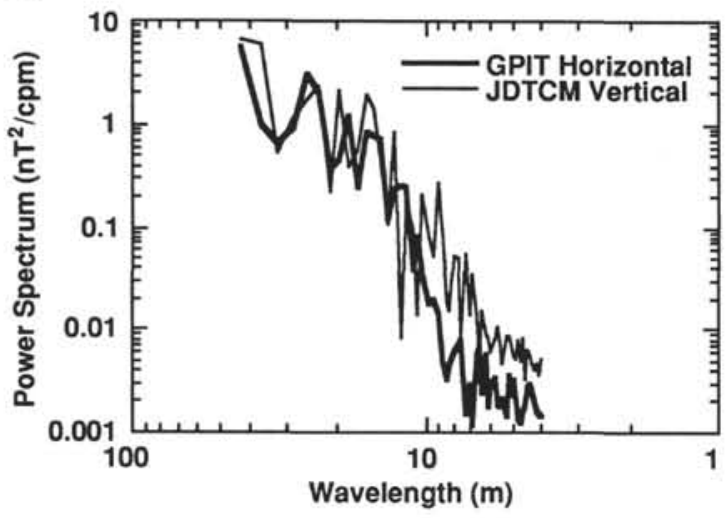

B

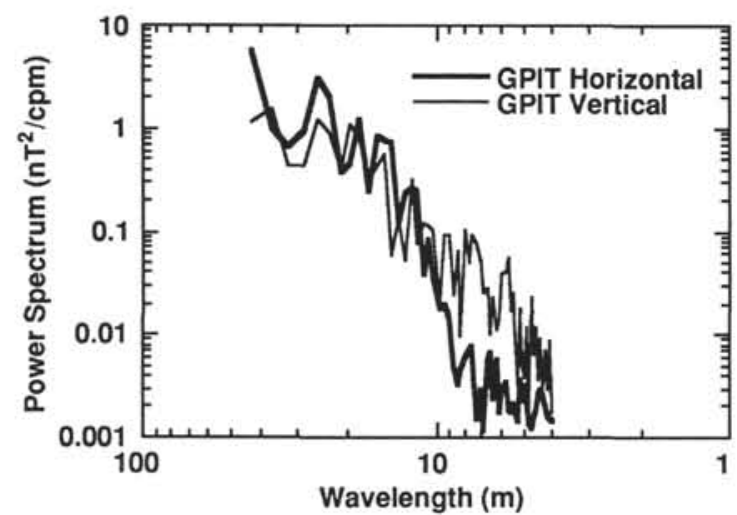

Figure 2. A. Power spectrum of horizontal magnetic field by the GPIT and vertical magnetic field by the JDTCM. B. Power spectrum of horizontal and vertical magnetic field by the GPIT.

The mean magnetic field of the horizontal and vertical components obtained by the GPIT and the vertical component recorded by the JDTCM were calculated (Table 1) and subtracted from each magnetic variation. The polarity of magnetization in each magnetic subunit was also determined from the sign of both the GPIT horizontal and JDTCM vertical fields with respect to each mean value as well as discrete sample paleomagnetic results (Sager et al., this volume). However, it is difficult to determine magnetic boundaries arising from normal to reversed polarity changes or intensity variations of magnetization of volcaniclastic sediments. Weak magnetization of volcaniclastic sediment, which is usually less than $1 \mathrm{~A} / \mathrm{m}$, causes only small amplitudes of magnetic field variations $(<800 \mathrm{nT})$ at the magnetic boundaries (Fig. 4). Also, variations caused by turbidite boundaries can be several orders of magnitudes in magnetization. The amplitude of magnetic variation derived from the intensity change of magnetization is comparable to that from a normal-reversed magnetic boundary (Fig. 4). A highly variable intensity change is expected in Site 869 sediments (calcareous oozes with variable amounts of volcaniclastics), because those sediments consist of various kinds of materials having highly variable magnetic content. Therefore, Koenigsberger $(Q)$ ratio, the ratio of primary to induced magnetization, the intensity of natural remanent magnetization (NRM), and inclination of characteristic remanent magnetization (ChRM) from discrete sample paleomagnetic results were used to constrain the determination of the polarity of magnetization.

\section{RESULTS}

Magnetic field variations of the horizontal and vertical components obtained by the GPIT and the vertical component recorded by the
Table 2. Magnetic units and magnetization in each magnetic unit from downhole magnetometer logs.

\begin{tabular}{|c|c|c|c|c|c|c|}
\hline \multicolumn{2}{|c|}{$\begin{array}{l}\text { Magnetic } \\
\text { unit }\end{array}$} & \multirow{2}{*}{$\begin{array}{c}\begin{array}{c}\text { Depth } \\
\text { (mbsf) }\end{array} \\
<<293 \\
293-319\end{array}$} & \multirow{2}{*}{$\begin{array}{c}\text { Hemisphere } \\
\text { Southern } \\
-\end{array}$} & \multirow{2}{*}{$\begin{array}{c}\text { Polarity } \\
\text { Normal } \\
-\end{array}$} & \multirow{2}{*}{$\begin{array}{c}\begin{array}{c}\text { Apparent } \\
\text { inclination } \\
\text { (degrees) }\end{array} \\
1.2 \pm 0.83\end{array}$} & \multirow{2}{*}{$\begin{array}{c}\begin{array}{c}\text { Correlation } \\
\text { coefficient }\end{array} \\
0.19\end{array}$} \\
\hline 1 & $\begin{array}{l}\mathrm{a} \\
\mathrm{b}\end{array}$ & & & & & \\
\hline 2 & $\begin{array}{l}\mathrm{a} \\
\mathrm{b} \\
\mathrm{c} \\
\mathrm{d} \\
\mathrm{e}\end{array}$ & $\begin{array}{l}319-330 \\
330-338 \\
338-344 \\
344-378 \\
378-403\end{array}$ & $\begin{array}{l}\text { Southern } \\
\text { Southern } \\
\text { Southern } \\
\text { Southern }\end{array}$ & $\begin{array}{c}\text { Reverse? } \\
\text { Reverse } \\
\text { Normal? } \\
\text { Reverse }\end{array}$ & $1.7 \pm 1.7$ & 0.11 \\
\hline 3 & $\begin{array}{l}\mathrm{a} \\
\mathrm{b}\end{array}$ & $\begin{array}{l}403-441 \\
441-450\end{array}$ & $\begin{array}{l}\text { Southern } \\
\text { Northern }\end{array}$ & $\begin{array}{l}\text { Normal? } \\
\text { Normal? }\end{array}$ & $6.9 \pm 1.3$ & 0.63 \\
\hline $\begin{array}{l}4 \\
5\end{array}$ & & $\begin{array}{l}450-482 \\
482-531\end{array}$ & $\begin{array}{l}\text { Southern } \\
\text { Southern }\end{array}$ & $\begin{array}{l}\text { Normal } \\
\text { Normal }\end{array}$ & $\begin{array}{l}13.6 \pm 1.9 \\
23.2 \pm 3.1\end{array}$ & $\begin{array}{l}0.78 \\
0.70\end{array}$ \\
\hline 6 & $\begin{array}{l}\mathrm{a} \\
\mathrm{b}\end{array}$ & $\begin{array}{l}531-583 \\
583-651\end{array}$ & $\begin{array}{l}\text { Southem } \\
\text { Southern }\end{array}$ & $\begin{array}{l}\text { Normal } \\
\text { Normal }\end{array}$ & $22.9 \pm 1.9$ & 0.72 \\
\hline $\begin{array}{c}7 \\
\text { All }\end{array}$ & & $\begin{array}{c}>651 \\
-\end{array}$ & Southem & Normal & $\begin{array}{l}21.2 \pm 2.9 \\
17.1 \pm 1.0\end{array}$ & $\begin{array}{l}0.65 \\
0.61\end{array}$ \\
\hline
\end{tabular}

JDTCM are shown in Figure 5, with the mean of each magnetic variation subtracted (Table 1). Variations of the GPIT ISDDM and those of the absolute-value of the spatial differential of the JDTCM vertical magnetic field are also shown in Figure 5. $Q$ ratio, intensity of NRM, and inclination of ChRM from discrete sample paleomagnetic study are shown in Figure 6. The boundaries, apparent inclination, and polarity of magnetization in each magnetic units and subunits are summarized in Table 2.

The trend of the vertical component field variations suggests that the magnetization of the deeper sediments (magnetic Units 4-7) was acquired in the Southern Hemisphere during a normal chron (i.e., the level of the vertical component gradually increases with depth). Below magnetic Unit 4, the boundaries of the magnetic units are marked by a set of sharp magnetic field decreases and increases in both the horizontal and vertical components. The vertical component of the magnetic field is virtually always positive relative to the mean value; negative values are not seen except in the vicinity of a few boundaries. This indicates that the magnetization of the lower sediments has a negative inclination. Shorter wavelength field variations in both the horizontal and vertical components in the lower parts of the section typically exhibit almost the same change in the same sense. This also shows that such magnetization originated in the Southern Hemisphere. The average $Q$ ratio within this zone is higher than that of the upper part of the sediments. Assuming that magnetization consists of remanent and induced magnetization, higher $Q$ ratios reflect dominance of a remanent magnetization. This result agrees with paleomagnetic results that show these sediments represent the Cretaceous Normal Superchron and were magnetized in the Southern Hemisphere (Sager et al., this volume).

Although complicated magnetic field variations were obtained in the upper part of sediments from magnetic Units 1 to 3, magnetic field variation in the horizontal component exhibits almost the same change as in the vertical component, indicating that most of the magnetization was acquired in the southern hemisphere. However, in magnetic Subunit $3 b$, the horizontal and vertical components vary in opposite senses, indicating that the magnetization originated in the Northern Hemisphere. The Northern Hemisphere magnetization is most likely an induced or viscous magnetization. The hemisphere and polarity of the magnetization in magnetic Subunits $1 \mathrm{~b}$ and $2 \mathrm{e}$ were not identified.

A good correlation between the spatial differentials was obtained below magnetic Unit 3 . The apparent inclination obtained by using all spatial differential values is $17.1^{\circ}$. Apparent inclinations for individual magnetic units range from $1.2^{\circ}$ to $23.2^{\circ}$.

\section{DISCUSSION}

A close correspondence between magnetic variations from downhole magnetometer logs and $Q$ ratio from discrete core samples is 
Figure 3. Correlation between horizontal and vertical component spatial differentials in each magnetic unit and all magnetic units. Regression lines and equations are also shown.
Magnetic Unit 1 $y=0.0425 x+1.29 R=0.185$

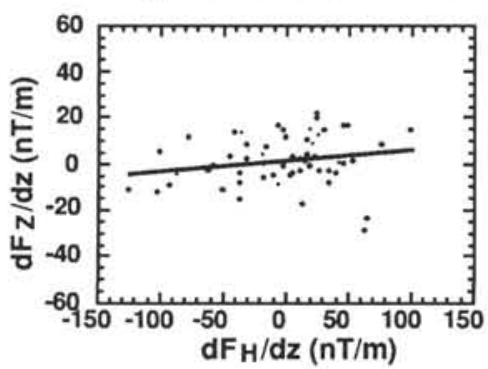

Magnetic Unit 2 $y=0.0602 x-0.0695 \quad R=0.113$

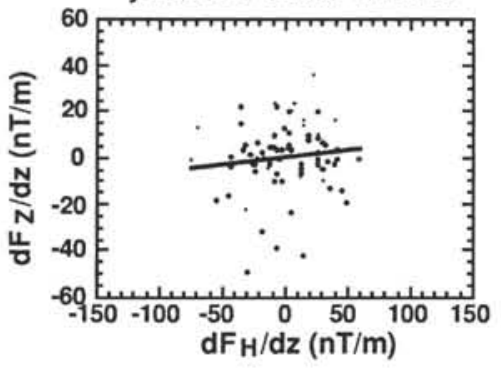

Magnetic Unit 3 $y=0.242 x+1.20 R=0.630$

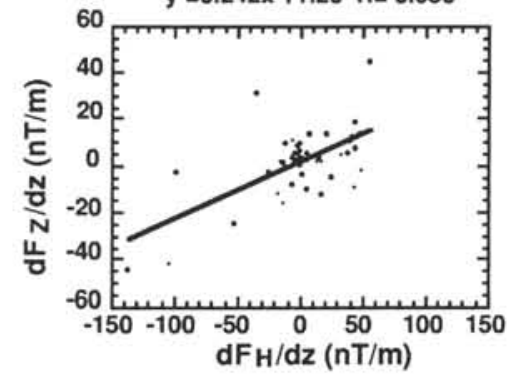

Magnetic Unit 4 $y=0.483 x+2.01 \quad R=0.780$

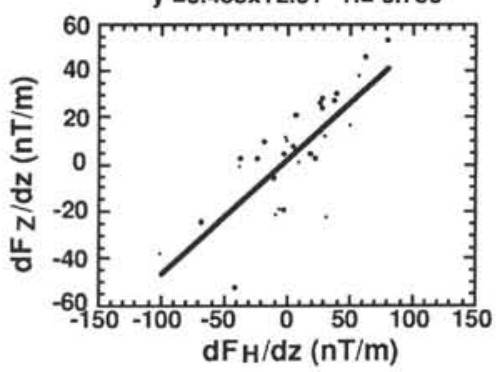

Magnetic Unit 5 $y=0.858 x+4.03 R=0.697$

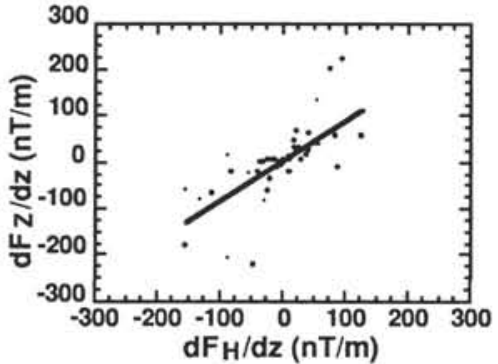

Magnetic Unit 6 $y=0.845 x-0.415 \quad R=0.716$

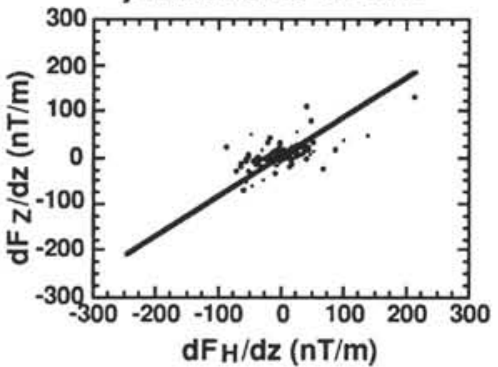

Magnetic Unit 7 $y=0.777 x-3.16 \quad R=0.647$

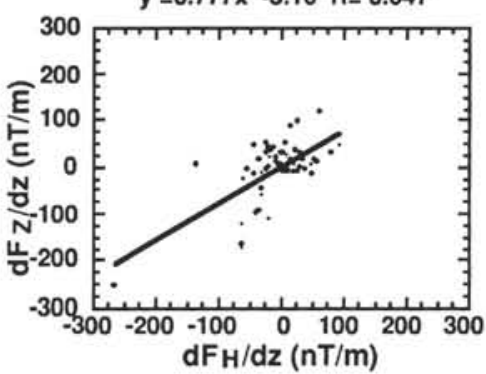

All

$y=0.614 x+0.385 R=0.605$

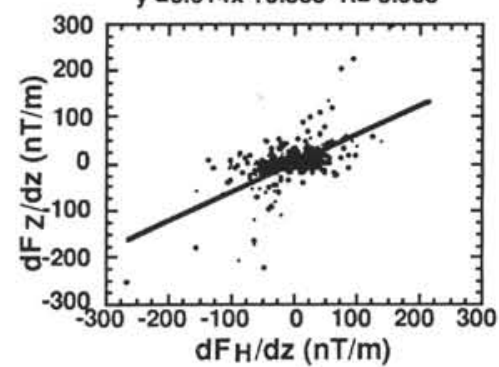

observed, suggesting that the magnetic variations and the apparent inclination from downhole logs are affected by induced magnetization. Paleomagnetic measurements show that the deeper part of sediments at Site 869 were magnetized in the Southern Hemisphere during a normal chron, so the induced or viscous magnetization will cause the inclination to appear shallowed. Apparent inclinations in magnetic Units 3 and 4 are the least reliable, but give values shallower than those calculated from magnetic Units 5 through 7 . The latter give inclinations of $21.2^{\circ}$ to $23.2^{\circ}$. Paleomagnetic study also shows two distinct inclination groups, $-23.2^{\circ}$ and $-33.3^{\circ}$ with the former being typical above Subunit IIID (Sager et al., this volume). The apparent inclination results are similar, but shallower than the inclination values from the paleomagnetic study. Assuming that only induced magnetization is added to the primary magnetization, the $Q$ ratio (Koenigsberger ratio) from downhole magnetometer logs in magnetic Units 3 and 4 ranges from 1 to 2.5 , while that in magnetic Units 5 through 7 is almost 3. These are in good agreement with $Q$ ratios from discrete sample paleomagnetic study.

The magnetization in magnetic Subunit 3a possibly indicates an origin in the Southern Hemisphere during a normal polarity chron. Horizontal and vertical magnetic fields increase with depth from the upper boundary of magnetic Subunit 3a, implying that magnetization in the Southern Hemisphere during a normal chron (Fig. 7). $Q$ ratio and NRM intensity from discrete sample paleomagnetic study also increase around the upper boundary of Magnetic Subunit 3a. Paleomagnetic study further suggests a negative inclination below about 380 
A



B

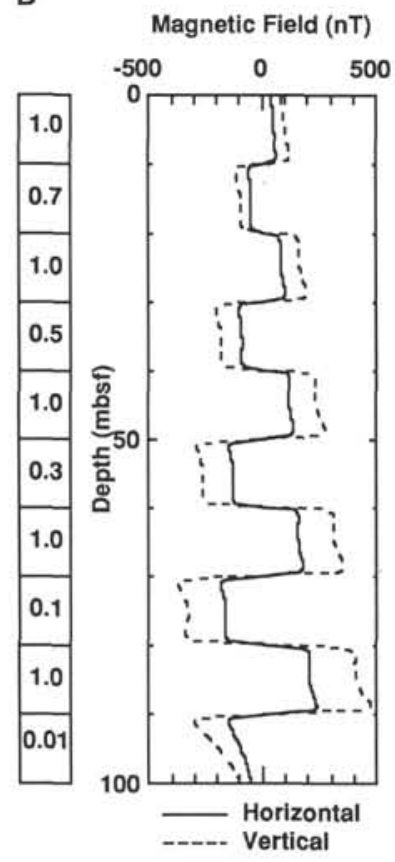

field decrease and suggest that the magnetization originated in the Southern Hemisphere during a reversed polarity chron. Increases in both the horizontal and vertical components of magnetic-field are interpreted as a decrease in intensity of magnetization and/or the change in the polarity of magnetization. Paleomagnetic study suggests that a reversed polarity zone is recognized from 324 to 382 mbsf, corresponding to the zone from magnetic Subunits $2 \mathrm{a}$ to $2 \mathrm{~d}$ (Sager, Winterer, Firth, et al., 1993; Sager et al., this volume). However, negative inclination also was observed amid the positive inclination zone around magnetic Unit $2 \mathrm{c}$ by paleomagnetic study (Sager et al., this volume). Although $Q$ ratio and NRM intensity were not obtained from this zone, significant changes in these parameters are not observed in the lower part of magnetic Subunit $2 b$ and the upper part of magnetic Subunit 2d.

A short normal polarity interval probably is implied from magnetic variations in magnetic Subunit $2 \mathrm{c}$ as well as paleomagnetic studies. The reversed zone has been interpreted as Chron 33R (Sager et al, this volume). This reversed polarity chron is constrained by a nannofossil age (Mütterlose, this volume). However, there is no evidence for such a short normal polarity interval in a marine magnetic anomaly during this chron (Cande and Kent, 1992). We also note that other explanations can be invoked to cause this apparent short normal polarity interval within Chron 33R. It is possible that there is a zone of chemical alteration, undetected as a result of poor core recovery, that the magnetization represents a remagnetization acquired during Chron $32 \mathrm{~N}$. Further comparison with onshore magnetostratigraphic section are needed.

Because magnetic variations can be caused both by remanent and induced magnetization, downhole susceptibility logs would greatly complement future downhole magnetometer logs. Downhole magnetometer logs give continuous information concerning the magnetization of surrounding materials, which is not available at times of poor core recovery. A shallower inclination value from downhole magnetometer readings was obtained at this site than was obtained from paleomagnetic study, which was most likely caused by induced or viscous magnetization. If susceptibility log data are available and the viscous overprinting effect is negligible, corrections for induced magnetization can be made to magnetic variations from downhole magnetometer logs, and magnetic variations caused by natural remanent magnetization (NRM) could be obtained directly. Sedimentary rocks in the ocean usually have a low $Q$ ratio and a large induced component of magnetization. Downhole magnetometer logs, combined with downhole susceptibility logs, are necessary to obtain good results in the sedimentary section. Moreover, if fully oriented data can be obtained (e.g., magnetometer with gyro), the declination of the magnetization of surrounding material could also be found.

\section{SUMMARY AND CONCLUSIONS}

Magnetic field variations from downhole magnetometer logs were collected at Site 869, where the major lithologic constituent is volcaniclastics. Magnetic field data obtained by the general purpose inclinometer tool (GPIT) supplied additional information concerning magnetization in the borehole. Absolute values of the magnetic field recorded by the GPIT were significantly different from those recorded by the JDTCM. The origin of this discrepancy has not been identified, but does not affect the conclusions of this study.

The magnetic field variations suggest that almost all the magnetization was acquired in the Southern Hemisphere. Below $380 \mathrm{mbsf}$, magnetization was acquired in the Southern Hemisphere during a normal chron. A close correspondence between magnetic variations from downhole magnetometer logs and $Q$ ratios from discrete core sample suggests that the magnetic variations from downhole logs are affected by induced magnetization. A reversed magnetization zone is suggested between 319 and $378 \mathrm{mbsf}$ and is interpreted as reversed polarity Chron 33R consistent with previous paleomagnetic results. Magnetic 


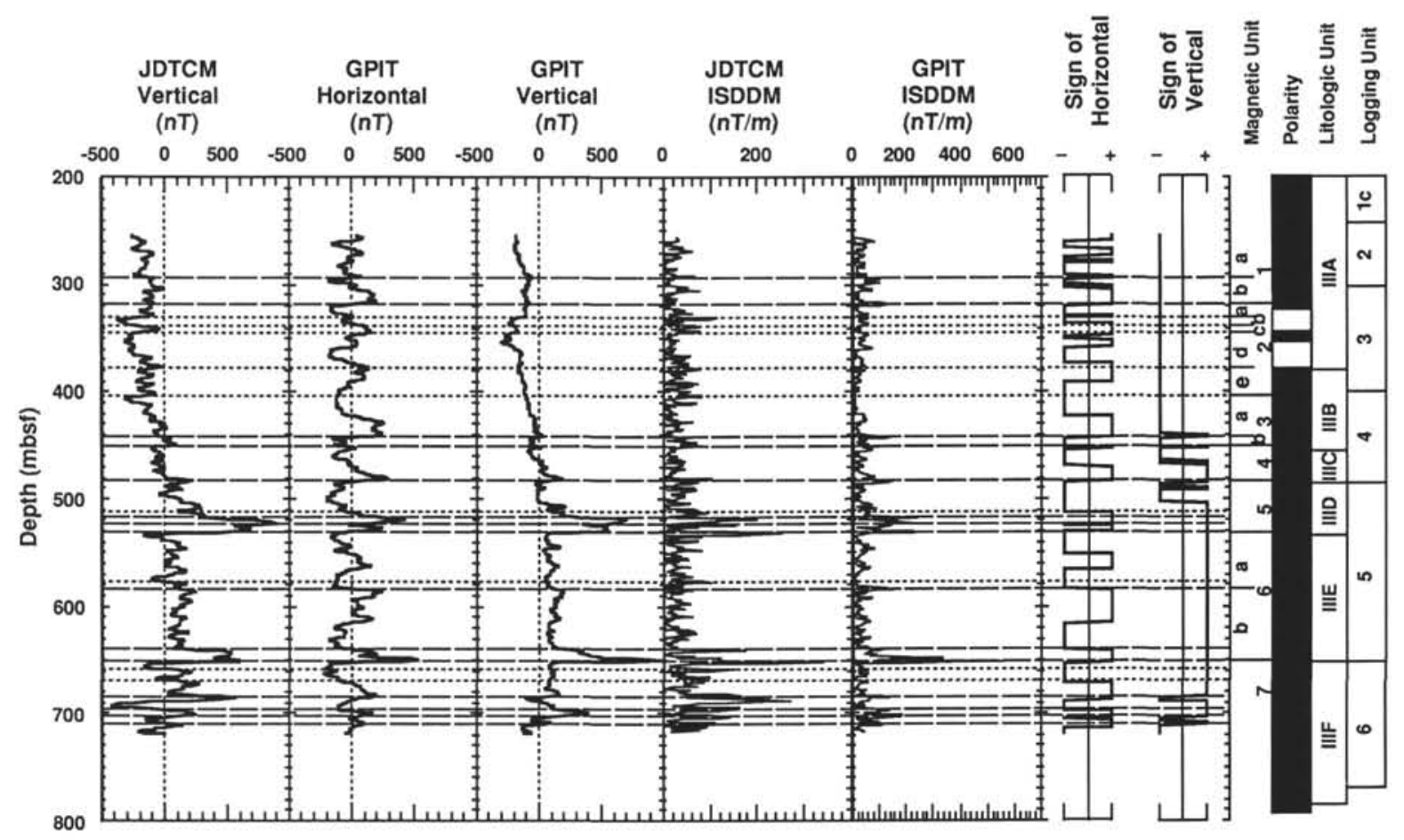

Figure 5. Horizontal and vertical component magnetic field variations after subtracting the mean value, and variations of the intensity of the spatial differentials of the downhole magnetic field (ISDDM). ISDDM measurements with the JDTCM were calculated using only the vertical component of the magnetic field. Signs of the GPIT horizontal and vertical components are relative to the mean value of each component. Magnetic units defined by ISDDM are also shown. Lithologic units and logging units are from Sager, Winterer, Firth, et al. (1993). Magnetic polarity is from Sager et al. (this volume), and solid and open areas indicate normal and reversed polarity, respectively. Dashed lines show the magnetic boundaries suggested by the ISDDM of both the JDTCM and GPIT, and dotted line denotes those suggested only by the ISDDM of JDTCM.

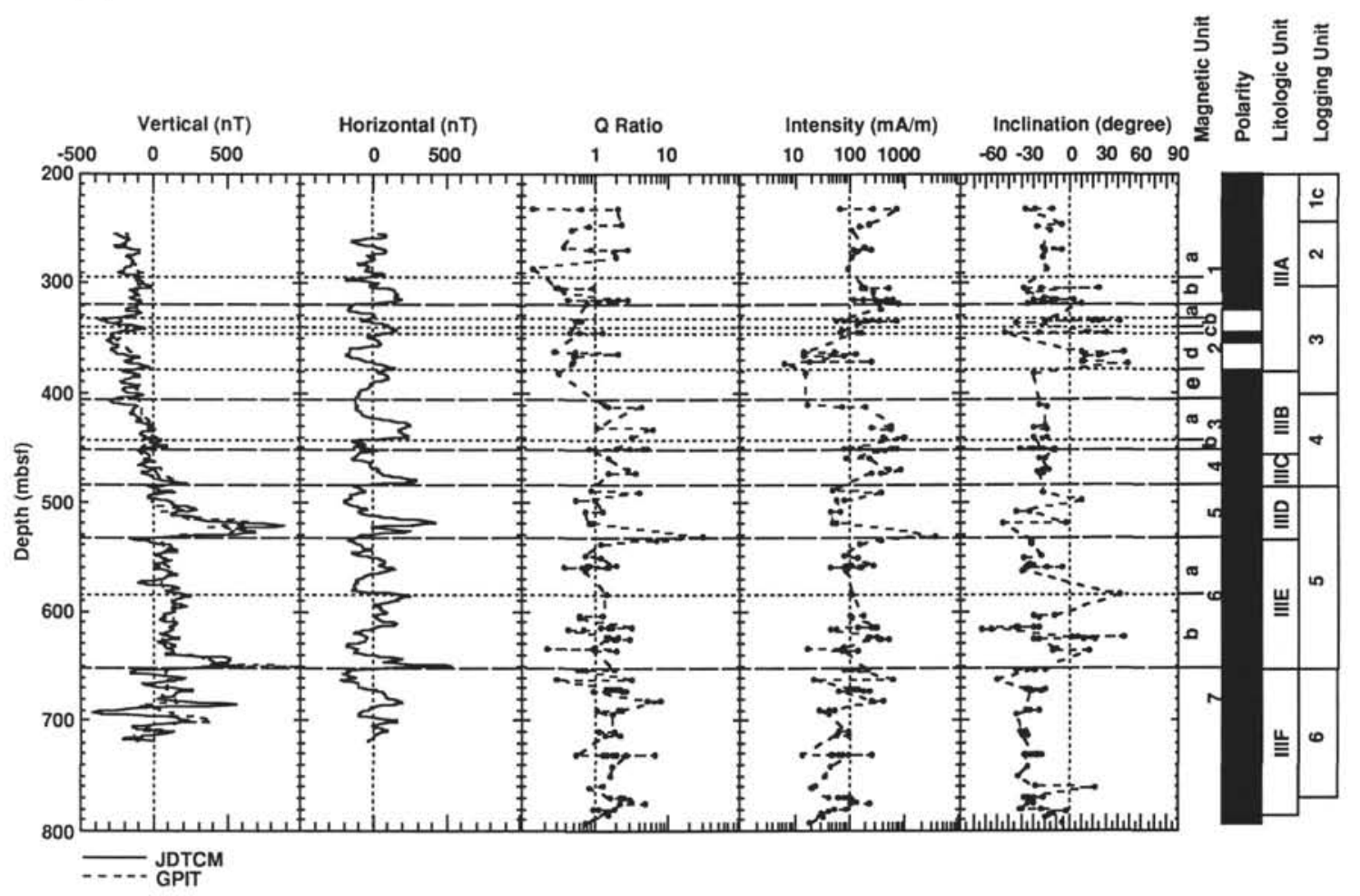

Figure 6. Horizontal and vertical component magnetic field variations by the JDTCM and GPIT, and Koenigsberger $(Q)$ ratio, the ratio of primary to induced magnetization, the intensity of natural remanent Magnetization, and inclination of characteristic remanent magnetization (ChRM) from discrete sample paleomagnetic results. Dashed lines show the magnetic boundaries of magnetic units, and dotted line denotes those of magnetic subunits. Lithologic and logging units and magnetic polarity are the same as those in Figure 5. 


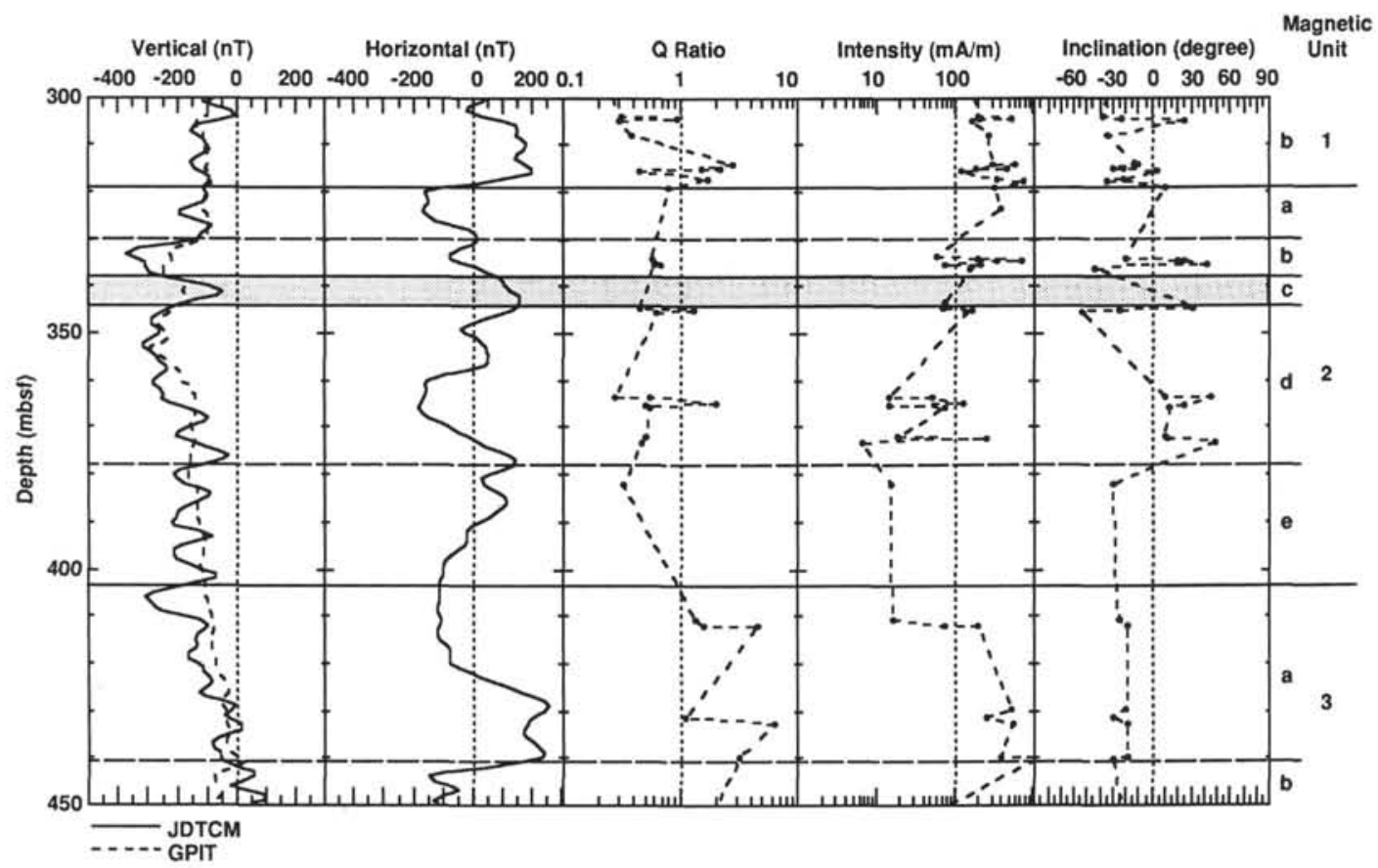

Figure 7. Horizontal and vertical component magnetic field variations by the JDTCM and GPIT, and Koenigsberger $(Q)$ ratio, the ratio of primary to induced magnetization, the intensity of natural remanent magnetization, and inclination of characteristic remanent magnetization (ChRM) from discrete sample paleomagnetic results between 300 and 450 mbsf. Dashed lines show the magnetic boundaries of magnetic units, and dotted line denotes those of magnetic subunits. Magnetic units and subunits are shown at the right. Shaded zone indicates a possible short normal polarity interval.

field variations between 338 and 344 mbsf in the reversed polarity zone imply a possible short normal polarity interval in Chron 33R.

Two apparent inclination groups $\left(6.9^{\circ}-13.6^{\circ}\right.$ and about $\left.22^{\circ}\right)$ were obtained from downhole magnetometer logs. The apparent inclinations are shallower than those determined from paleomagnetic study. Induced magnetization most likely caused this apparent inclination-shallowing.

\section{ACKNOWLEDGMENTS}

Y.N. thanks N. Seama and C. Itota for discussions. We also thank $\mathrm{H}$. Kinoshita and anonymous reviewer for their reviews and helpful comments. The Japanese downhole three-component magnetometer was developed and fabricated by Meisei Electronic Co., Inc. The magnetometer was calibrated at Kakioka Magnetic Observatory. Y.N. is grateful to the members of the Geochemical Research Department, Meteorological Research Institute, for their understanding and interest in our observations. We thank the Ocean Research Institute, University of Tokyo, and the Ocean Drilling Program for the opportunity of participating in Leg 143.

\section{REFERENCES*}

Cande, S.C., and Kent, D.V., 1992. A new geomagnetic polarity time scale for the Late Cretaceous and Cenozoic. J. Geophys. Res., 97:13917-13951.
Hamano, Y., and Kinoshita, H., 1990. Magnetization of the oceanic crust inferred from magnetic logging in Hole 395A. In Detrick, R., Honnorez, J., Bryan, W.B., Juteau, T., et al., Proc. ODP, Sci. Results, 106/109: College Station, TX (Ocean Drilling Program), 223-229.

IAGA Division V Working Group 8, 1991. International Geo-magnetic Reference Field 1991 revision. J. Geomagn. Geoelectr., 43:1007-1012.

Kinoshita, H., Furuta, T., and Pariso, J., 1989. Downhole magnetic field measurements and paleomagnetism, Hole 504B, Costa Rica Ridge. In Becker, K., Sakai, H., et al., Proc. ODP, Sci. Results, 111: College Station, TX (Ocean Drilling Program), 147-156.

Sager, W.W., Winterer, E.L., Firth, J.V., et al., 1993. Proc. ODP, Init. Repts., 143: College Station, TX (Ocean Drilling Program).

\footnotetext{
-Abbreviations for names of organizations and publication titles in ODP reference lists follow the style given in Chemical Abstracts Service Source Index (published by American Chemical Society).
}

Date of initial receipt: 1 December 1993

Date of acceptance: 23 May 1994

Ms 143SR-238 